\title{
HSL Renk Uzayında Görüntü İşleme ve Morfolojik İşlemler Kullanarak Gerçek Zamanlı Nesne Tespiti ve Sınıflandırması
}

\author{
Doğucan Yağmur ${ }^{1 *}$, Gökhan Atalı \\ ${ }^{1 *}$ Sakarya Uygulamalı Bilimler Üniversitesi, Teknoloji Fakültesi, Mekatronik Mühendisliği Bölümü, Sakarya, Türkiye, (ORCID: 0000-0001-9153-7636), \\ y190010001@subu.edu.tr \\ ${ }^{2}$ Sakarya Uygulamalı Bilimler Üniversitesi, Teknoloji Fakültesi, Mekatronik Mühendisliği Bölümü, Sakarya, Türkiye, (ORCID: 0000-0003-1215-9249), \\ gatali@subu.edu.tr
}

(1st International Conference on Applied Engineering and Natural Sciences ICAENS 2021, November 1-3, 2021)

(DOI: 10.31590/ejosat.1009678)

ATIF/REFERENCE: Yağmur, D. \& Atalı, G. (2021). HSL Renk Uzayında Görüntü İşleme ve Morfolojik İşlemler Kullanarak Gerçek Zamanlı Nesne Tespiti ve Sınıflandırması. Avrupa Bilim ve Teknoloji Dergisi, (28), 607-613.

$\ddot{O} \mathbf{z}$

Görüntü işleme; tanıma, tespit, sınıflandırma, takip ve bölütleme gibi amaçlar için kullanılan yaygın bir yöntemdir. Bu yöntem, dağıtık şekilde yüzeyde bulunan materyallerin konum ve boyut gibi bilgilerinin toplanabilmesi için oldukça hızlı ve güvenilir sonuçlar üretmektedir. Özellikle, yeni nesil üretim hatlarında farklı boyutlarda rastgele dizili gelebilen ürünlerin tespiti için kullanılan görüntü işleme teknikleri gelişen teknolojiler arasında yer almaktadır. Bu çalışmada farklı çaplara sahip ürünlerin üretim hatlarında dağıtık bir şekilde bulunduğu ortamların örneklenmesi amacıyla giriş parametresi olarak madeni para kullanılmıştır. Öncelikle gerçek zamanlı olarak kamera ile alınan görüntünün HSL türünde renk uzayı çıkarıldıktan sonra gerçek dünya birimlerinde ölçüm yapabilmek için kalibrasyon işlemi gerçekleştirilmiştir. Daha sonra gri tonlamalı görüntüden renk eşiği oluşturulup piksel değeri ayarlanmasıyla madeni para ile bulunduğu yüzey birbirinden ayrıklaştırılmıştır. Son olarak hataya sebep oluşturabilecek parazitler filtrelenmiş ve ardından ölçüm sonuçları alan cinsinden hesaplanarak madeni paraların sayıları tespit edilerek sınıflandırılmıştır. Bu işlemler için gerekli olan hesaplamalar LabVIEW yazılım ortamında gerçekleştirilmiş ve sonuçlar anlık olarak görüntülenmiştir. Sonuç olarak, uygulanan görüntü işleme teknikleri ile tespit edilen yüzeydeki madeni paraların alan bilgileri kullanılarak gerçek boyutlara oranla ortalama doğrulukları tespit edilerek yazılımın başarım oranı çıkarılmıştır.

Anahtar Kelimeler: Görüntü işleme, Bölütleme, Sınıflandırma, HSL renk uzayı, LabVIEW.

\section{Real-Time Object Detection and Classification Using Image Processing and Morphological Technique in HSL Color Space}

\begin{abstract}
Image processing is a common method used for purposes such as recognition, detection, classification, tracking and segmentation. This method produces very fast and reliable results in order to data acquisition such as the position and size of the materials on the surface in a distributed manner. Especially, image processing techniques used for the detection of random products in new generation production lines are among the developing technologies. In this study, a coin was used as an input parameter in order to sample the environments where products with different diameters are distributed on the production lines. First of all, the color space is extracted in the HSL of the image taken with the real time camera and calibration process has been carried out in order to make measurements in real world units. Then, by creating a color threshold from the grayscale image and adjusting the pixel value, the coin and the surface it is located on are discretized from each other. Finally, the parasites have been filtered out, and then the measurement results have been calculated in terms of area, and the numbers of the coins were determined and classified. All calculations required for these processes have been performed in the LabVIEW and the results displayed real time. As a result, by using the area information of the coins on the surface
\end{abstract}

* Sorumlu Yazar: y190010001@,subu.edu.tr 
determined by the applied image processing techniques, the average accuracy of the coins compared to the real sizes was determined and the performance rate of the software has been calculated.

Keywords: Image processing, Coin detection, Classification, HLS color space, LabVIEW.

\section{Giriş}

Gelişen teknoloji ile birlikte endüstrideki üretim hızı artmış ve bunun sonucunda üretim sistemlerinin daha yüksek verimlilikle çalışma ihtiyacı doğmuştur. Çünkü hata tespitinin hızlı bir şekilde gerçekleştirilmemesi durumunda daha kısa sürede daha çok ürünün hatalı üretilmesine ve bunun sonucunda maliyetin artmasına sebep olmaktadır.

Üretim sonucunda ortaya çıkan ürünlerin kalite kontrolden geçirilerek hatalı ürün olup olmadığ $\breve{1}_{1}$ tespit edilebilmesi için el, göz veya ölçüm aletleriyle gerçekleştirilmekteyken bazı üretim sistemlerinde ise görüntü işleme teknikleri kullanılmaktadır. $\mathrm{Bu}$ kontrol sonucunda sistemin verimliliği hesaplanıp, sistem üzerinde iyileştirme çalışması yapılıp yapılmaması gerektiği ve yapılması gerekiyorsa bu çalışmanın acil olup olmadığına karar verilmektedir. Hata tespitinin görüntü işleme teknikleri ile gerçekleştirilmesi zaman ve maliyet bakımında kazanç sağlamakta ve operatör veya ölçüm aletlerinden kaynaklanan hatalar en aza inmektedir.

Atmaca'nın çalışmasında, örme kumaşların üretiminde gerçekleşen hataların tespiti için elde edilen görüntüler gri tonlara dönüştürülmüş ve histogram eşitlemesi uygulanmıştır. Görüntüdeki parazitlerin filtrelenmesi için araştırmacı orta filtreleme işlemi gerçekleştirmiş ve görüntülere Fourier Analizi uygulanarak sınıflandırmada kullanılacak özellikleri çıkarmıştır. Sınıflandırma işleminin en iyi şekilde gerçekleştirilmesi için yapay sinir ağları yöntemi ile bulanık bölgelere ayırma yöntemi kullanılmış, yapay sinir ağları yönteminin daha iyi sonuç verdiği görülmüştür (Atmaca, 2005). Tsai ve Tseng çalışmasında ton, doygunluk ve açıklık tabanlı olan HSL (hue, saturation, lightness) renk uzayını kullanarak renk algılama metodu üzerine çalışmışlardır. Ton ve doygunluk (HS) ile ton ve açıklık (HL) düzlemlerinden elde edilen bilgilerle nesne tanımlama işleminde çalışma süresini azaltmak ve algılama başarı oranını artırmak için yeni bir algoritma geliştirmişlerdir (Tsai \& Tseng, 2012). Ozan'ın yapmış olduğu çalışmada kusurlu yumurta analizi için görüntüsü alınan yumurtanın kusurlu bölgeleri tespit edilerek o bölgelere ait piksel sayıları hesaplanmıştır. Piksel sayıları daha önce belirlenen eşik değerinin üzerinde ise yumurta, kusurlu olarak nitelendirilmiştir. Yumurtaların boyut analizi için ise kusur bulunmayan yumurtalara ait piksel sayıları hesaplanmış ve daha önce belirlenen eşik değerlerine göre boyut sınıflandırması gerçekleştirilmiştir (Ozan, 2019). Bayram ve Yılmaz'ın yapmış olduğu çalışmada metal sektörü için kalite kontrol sistemi geliştirilmiştir. Araştırmacılar lazer kesim ünitesiyle kesilmiş sac levhaların üzerinde bulunan farklı boyutlardaki deliklerin toleransları üzerine çalışmışlardır. Çalışmalarında kamera ile alınan görüntülere önişlemler uygulanmış ve ardından Dairesel Hough Dönüşümü ile levhanın üzerinde yer alan deliklere ait sayı, çap ve konum bilgileri ölçülmüştür. Bu bilgiler, referans levhaya ait bilgiler ile karşılaştırılmış ve sac levhaların tolerans içinde olup olmadıkları tespit edilmiştir (Bayram \& Yılmaz, 2019). Yoldaş ve Sungur'un yapmış olduğu çalışmada alüminyum ekstrüzyon profil üretiminde kalite kontrolü gerçekleştirmek için kameradan alınan renkli görüntünün üzerinde gürültü giderme işlemleri gerçekleştirilmiş ve görüntü gri tonlarına dönüştürülmüştür. Ardından ikili görüntüye dönüştürülerek Canny kenar belirleme algoritması uygulanmıştır. Referans nesnenin görüntüdeki piksel değerleri, gerçek değerler ile oranlanarak piksel-mm dönüşümü formalize edilmiştir. Referans nesnenin bir kesitindeki gerçek ölçüsü ile görüntü işleme sonucu elde edilen ölçü karşılaştırılarak hata payı \%0,6 olarak belirlenmiştir (Yoldaş \& Sungur, 2020). Güvenoğlu ve Bağırgan'nın çalışmalarında kot kumaşlar üzerinde hata tespiti için MATLAB ortamında oluşturulmuş kumaş hata tespit yazılımı ile kameradan gelen kumaş yüzeyi görüntüleri gri tonlarına dönüştürülerek filtreleme işlemleri uygulanmıştır. Shearlet dönüşümü uygulanarak görüntülere ait öznitelik vektörleri elde edilmiştir. $\mathrm{Bu}$ bilgiler kullanılarak farklı hata türlerine ait sınıflandırma için yapay sinir ağlarında eğitim verisi olarak kullanılmış ve testi gerçekleştirilmiştir. K katmanlı çapraz doğrulama metodu ile daha önce elde edilen sonuçların doğruluğu test edilmiş ve ortalama doğruluk oranı \%94,453 olarak elde edilmiştir (Güvenoğlu \& Bağırgan, 2019). Özkan'ın yapmış olduğu çalışmada üretimdeki yumurtaların kalite kontrolleri gerçekleştirilmiş ve boyutlarına göre sınıflandırılmıştır. Görüntüsü alınan yumurtaların x ve y eksenlerindeki çapları bulunmuş ve V. G. Narushin yöntemi ile yumurtaların hacimleri hesaplanmıştır. Yumurtaların hacim ve öz kütle bilgileri kullanılarak ağırlıkları hesaplanmıştır. Kir piksellerinin sayısı, yumurtaya ait toplam piksel sayısına bölünerek yüzde cinsinden kir oranı hesaplanmıştır. Araştırmacı kir oranı ve ağırlık durumu bilgilerini kullanarak bulanık mantık yöntemi ile yumurtaların kalite ve ağırlık sınıflarını belirlemiştir (Özkan, 2012). Öztürk'ün yapmış olduğu çalışmada cam üretim sisteminde kalite kontrolü gerçekleştirmek için görüntü işleme teknikleri kullanılmıştır. Kırık, çatlak, çizik ve baloncuk gibi hataların tespiti için görüntülere LoG, Canny, dalgacı dönüşümü, hücresel sinir ağı ve Gabor bankası algoritmaları uygulanarak hatalar tespit edilmiş ve sonuçlar referans görüntüler ile karşılaştırılmıştır. Çalışma sonunda araştırmacı en başarılı modellerin \%91,46 ile hücresel sinir ağı ve \%89,55 ile Gabor bankası uygulamaları olduğu tespit etmiştir (Öztürk, 2015). Pınar ve arkadaşlarının yapmış oldukları çalışmada pamuk ipliğinden üretilmiş ve indigo boyarmaddesi ile boyanmış olan denim kumaşlarını hatalı-hatasız olarak sınıflandırmak için görüntü işleme tabanlı bir sistem geliştirilmiştir. Özellik matrisi oluşturularak lineer regresyon, J48 karar ağac1, DFF (Deep Feedforward Neural Network) sinir ağı, Naive Bayes, K-means algoritmalarına girdi verisi olarak verilmiştir ve J48 algoritmasının hatalı-hatasız kumaş ayrımında diğer yöntemlere göre daha doğru sonuç verdiği görülmüştür (Pınar vd., 2020). Burkert ve arkadaşları kısmi diferansiyel denklemlerin çözümü gibi karmaşık altyapılı işlemlerden kaçınarak iki çevrimli algoritma geliştirmişlerdir. Bu algoritma ile gerçek zamanlı uygulamalar için dijital görüntüler üzerinde alt piksel doğruluğu ile iyileştirme yaparak nesne tespiti yapılmıştır (Burkert vd., 2011). Zhan ve arkadaşları farklı çerçeve ve kenar algılamaya dayanan bir algoritma geliştirerek hareketli nesnelerin tespitini yapmışlardır. Canny detektörünü kullanarak geliştirdikleri algoritma ile çerçeve fark1 yöntemini iyileştirmişlerdir (Zhan vd., 2007). Şenel ve Çetişli' nin yapmış olduğu çalışmada görüntü işleme tekniklerini kullanılarak robot kol ile üretim bandındaki nesnelerin denetimi gerçekleştirilmiştir. Gömülü Linux işletim sistemi ve bu işletim sistemi ile çalışabilen QT 4.8 arayüz tasarımı ve kodlama programı kullanılmış. Elde edilen görüntü, ikili görüntüye dönüştürülmüş ve aşındırma işlemi uygulanarak görüntüdeki parazitler filtrelenmiştir. Canny kenar belirleme algoritmasıyla kenarlar belirlenmiş ve genişletme 
işlemiyle nesne içerisindeki boşluklar doldurulmuştur. Araştırmacılar yapmış oldukları çalışmada ikili görüntüdeki bütün piksel değerini toplamış ve daha önce belirlenen piksel değeri ile karşılaştırarak nesnenin hatalı olup olmadığına karar vermişlerdir. Bu karara bağlı olarak robot kolun hatalı olarak tanımlanan nesneleri ayrıştırmasını sağlamışlarıdır (Şenel \& Çetişli, 2015). Tüm bu araştırmaların araştırma konusu olan görüntü işleme ile nesne tespiti ve bunların entegre bir sistem ile sınıflandırılması güncel çalışma konuları arasında yer almaktadır (Ozkaya vd., 2018; Yıldırım \& Ozak, 2018).

Araştırmalar göstermektedir ki nesne ve özellikle hata tespiti aşamalarında görüntü işleme tekniklerinden oldukça fazla yararlanılmaktadır. $\mathrm{Bu}$ çalışmada, belirli bir yüzey üzerinde bulunan dairesel nesneleri tespit amaciyla madeni paralar örnek olarak kullanılmıştır. $\mathrm{Bu}$ dairesel madeni paraların çap ve alan bilgileri görüntü işleme teknikleri ile tespit edilmiş ve gerekli sınıflandırma yapılmıştır. Çalışmada nesne tespiti amacıyla sabit 1ş1k altında 1080p Full-HD WebCam (PK-910H) marka model webcam aracılığıyla elde edilen görüntüler, geliştirilen LabVIEW yazılım ortamına gerçek zamanlı olarak aktarılmış ve madeni paraların çap-alan bilgileri elde edilmiştir. Alan bilgileri kullanılarak tespit edilen yüzeydeki madeni paralar $1 \mathrm{TL}, 50 \mathrm{Krş}$, $25 \mathrm{Krş}, 10 \mathrm{Krş}$ ve $5 \mathrm{Kr}$ ş şeklinde sinıflandırılmış ve gerçek boyutlara oranla ortalama doğrulukları tespit edilerek başarım oranı çıkarılmıştır.

\section{2. Önerilen Sistem}

\subsection{Görüntünün Elde Edilmesi}

$\mathrm{Bu}$ çalışmada hatalı ürünler ile sağlam ürünlerin yüzey alanlarının aynı olmamasından yararlanılarak hata tespit ve sınıflandırma sistemi geliştirilmiştir. Bir web kamera ile madeni paraların görüntüleri alınırken hataları en aza indirmek için sabit bir ışık kaynağı ile ortam homojen bir şekilde aydınlatılmış ve kamera ise ölçüm yapılacak yüzeyin ağırlık merkezine dik açıyla bakacak şekilde $26 \mathrm{~cm}$ yükseklikte konumlandırılmıştır. Madeni paraların arka plandan daha kolay ayrılması için 16,50x28,50 cm boyutlarındaki siyah bir yüzey üzerinde görüntü alma işlemleri gerçekleştirilmiştir. Görüntüyü işleme ve sınıflandırma işlemleri için görsel programlama dili olan LabVIEW kullanılmıştır.

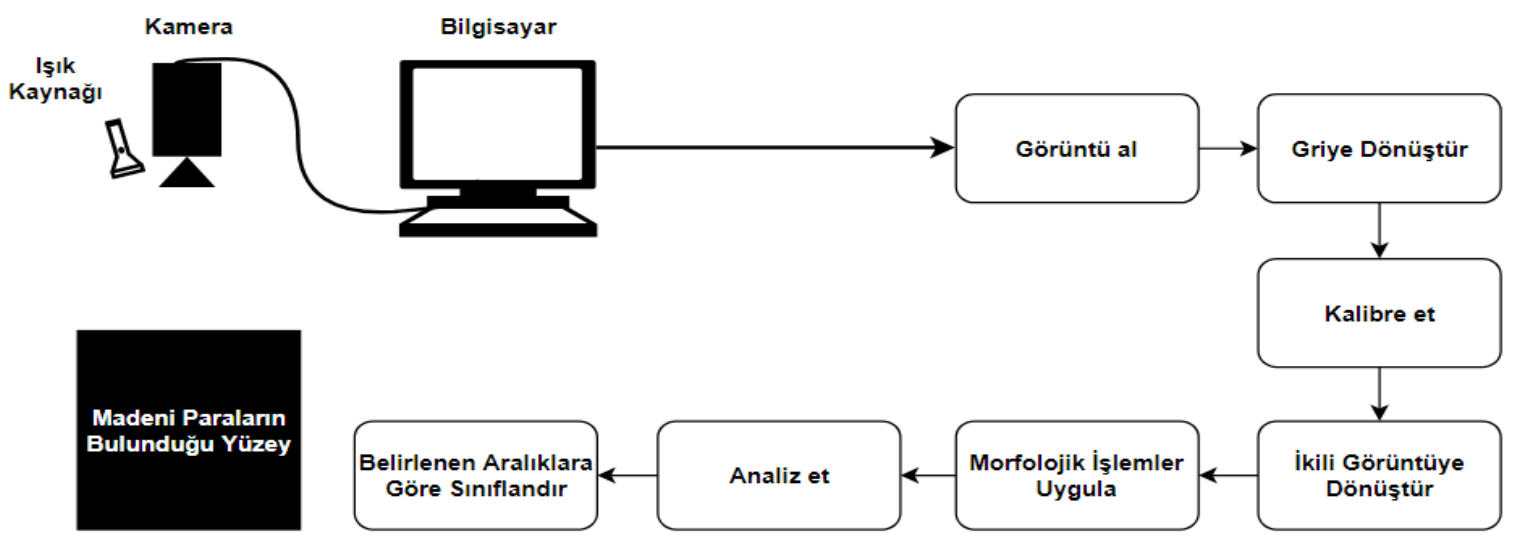

Şekil 1. Sistemin akış diyagramı

Şekil 2'de LabVIEW ortamında görüntünün elde edilmesinden sonra sırasıyla gerçekleştirilen işlem adımlarına yer verilmiştir. $\mathrm{Bu}$ adımlara ait detaylı bilgiler ise alt başlıklar şeklinde bu bölümün devamında yer almaktadır. Ayrıca Şekil 3 'te test verisi olarak kullanılan madeni paralara ait ön ve arka yüzler verilmiştir.

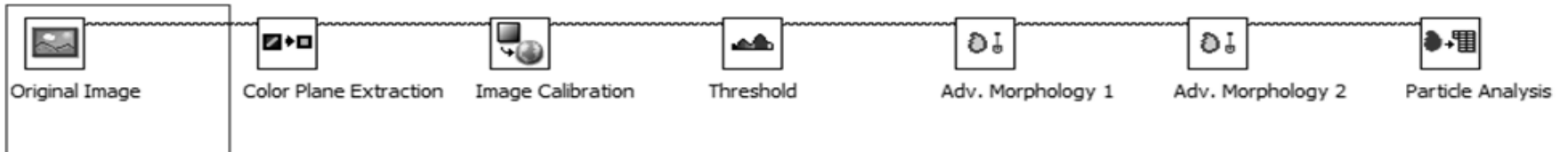

Şekil 2. Vision Asistant Modülü içerisindeki görüntü işleme adımları
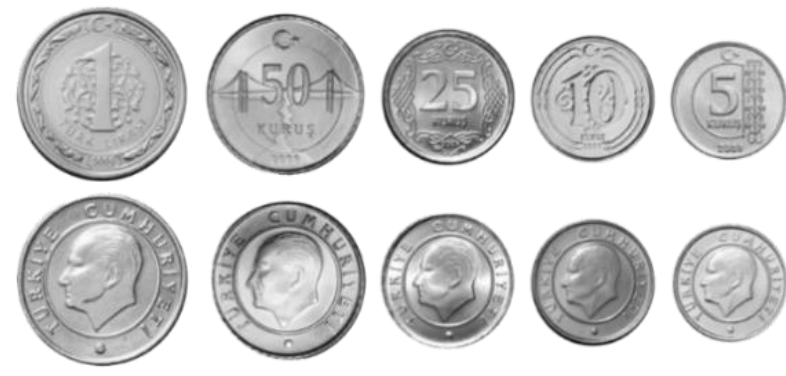

\subsection{Görüntü Kalibrasyonu}

Görüntüler piksel cinsinden bilgiler içerdiğinden dolayı ölçüm sonuçlarını gerçek dünya birimleri ile görüntülenmesi için sistemin kalibre edilmesi gerekmektedir. Web kameradan alınan RGB (red, green, blue) değerlerine sahip kalibrasyon ıgarasının görüntüsü gri tonlarına dönüştürülmüştür. Görüntüdeki noktaların merkezleri arasındaki yatay ve dikey doğrultudaki mesafelerin gerçek değeri olan $10 \mathrm{~mm}$ değeri sisteme girilmiş ve bu kalibrasyon matrisi sisteme öğretilmiştir.

Şekil 3. Test verisi olarak kullanılan madeni paralar 


\subsection{Segmantasyon}

Kalibrasyon işleminden sonra madeni paraların görüntüsü 1920x1080p çözünürlügüünde ve 32 bit renk derinliğinde olacak şekilde elde edilmiştir. Denklem (1) ile 32 bitlik RGB renk uzayındaki görüntü HSL renk uzayına dönüştürülerek parlaklık

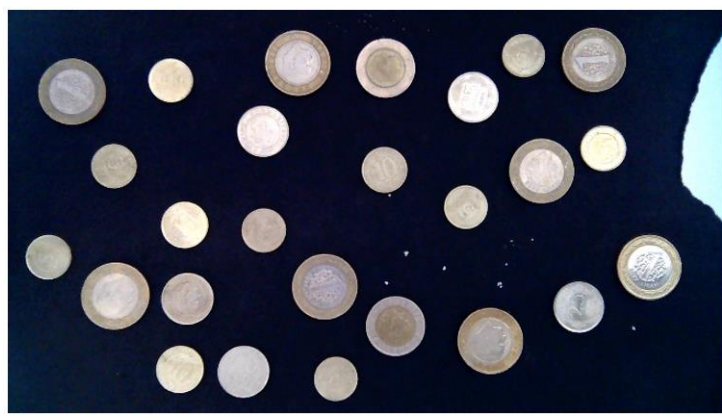

(a) düzlemi çıkarılmış (Şekil 4.a) ve ardından 8 bitlik gri tonlarında görüntü elde edilmiştir (Şekil 4.b). Bu sayede görüntü işleme adımlarının daha hızlı ve kolay bir şekilde gerçekleştirilmesi sağlanmıştır.

Gri tonlama de ğeri $=0,299 R+0,587 G+0,114 B$

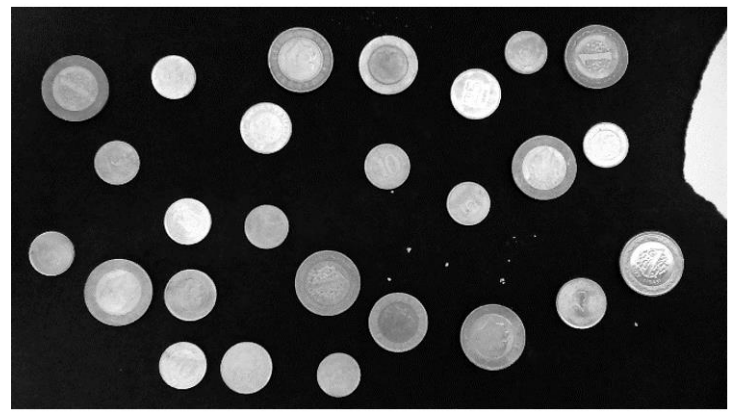

(b)

Şekil 4. (a) Orijinal görüntü (b) 8 bit gri tonlarındaki görüntü

Gri tonlarındaki görüntü ikili görüntüye dönüştürülerek madeni paranın arka plandan ayrılması sağlanmıştır. Bu işlem için gri tonlarındaki görüntüden histogram çıkarılmış ve bu histograma göre eşik değeri otomatik olarak belirlenmiştir. $\mathrm{Bu}$ yüzden otomatik eşikleme yöntemi, görüntüdeki parlaklık değerlerindeki değişimlerden sabit eşiğe göre daha az etkilenir (National Instruments, 2005). Şekil 5 'te verilen histogramda her gri seviyedeki piksel sayısı dikey eksen doğrultusunda gösterilirken, gri seviye değeri ise yatay eksen doğrultusunda gösterilmiştir.

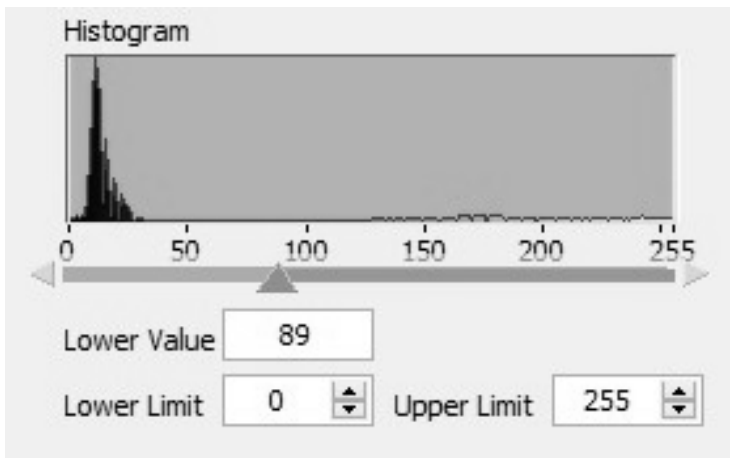

Şekil 5. Gri tonlarındaki görüntüye ait histogram

Otomatik eşikleme tekniklerinden metrik metodunun kullanılmasıyla bulunan eşik değeri, aşağıdaki ifadenin en aza indirildiği k piksel değeridir (National Instruments, 2003a).

$$
\sum_{i=0}^{i=k} h(i)\left|\left(i-\mu_{1}\right)\right|+\sum_{i=k+1}^{i=N-1} h(i)\left|\left(i-\mu_{2}\right)\right|
$$

0 ile $\mathrm{k}$ arasındaki piksel değerlerinin ortalaması $\mu_{1}, \mathrm{k}+1$ ile 255 arasındaki piksel değerlerinin ortalaması $\mu_{2}$, her gri seviyedeki piksel sayısı h(i), gri seviye değeri i, toplam gri seviye sayısı ise N'dir ve 8 bitlik görüntü için değeri 256'dır (National Instruments, 2003a).
Bu çalışmada gerçekleştirilen yazılımda parlak yüzeyler lojik 1, karanlık yüzeyler lojik 0 olarak ayarlanmıştır. Gri tonlamalı görüntüye ait piksel değerleri, eşik değerine eşit veya eşik değerinden küçük ise piksel değerleri 0 , eşik değerinden büyük ise piksel değerleri 1 yapılarak ikili görüntü oluşturulmuştur. 1 değerine sahip pikseller beyaz, 0 değerine sahip pikseller ise siyah renk ile gösterilmiştir (Şekil 6).

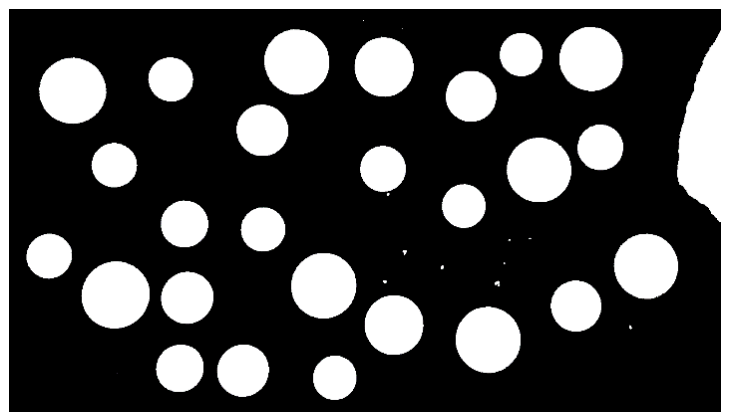

Şekil 6. 1 bitlik ikili görüntü

Gelişmiş morfolojik işlemler pikseller yerine parçacıklar üzerinde yoğunlaşarak en iyi görüntüyü elde etmeyi sağlamaktadır (National Instruments, 2003a). Bu nedenle Şekil 6'daki elde edilen ikili görüntü üzerinde, gelişmiş morfolojik işlemler uygulayarak ölçüm yapılacak görüntüde hatalara neden olabilecek parçacıklar ve nesneler ortadan kaldırılmıştır.

Gerçekleştirilen ilk işlemde siyah yüzey üzerinde bulunan ve genişlikleri N-1 piksel veya daha küçük olan parçacıklar, filtre boyutu N olan bir filtre ile ortadan kaldırılmıştır. Parçacıkların filtrelenmesi için gereken aşındırma sayısı, iterasyon sayısı ile belirtilerek (N-1)/2 aşındırmadan sonra parçacıklar filtrelenmektedir. $\mathrm{Bu}$ çalışmada iterasyon sayısı 15 olarak belirlenmiş ve bu işlem sonucunda görüntü iyileştirilmiştir (Şekil 7.a). 


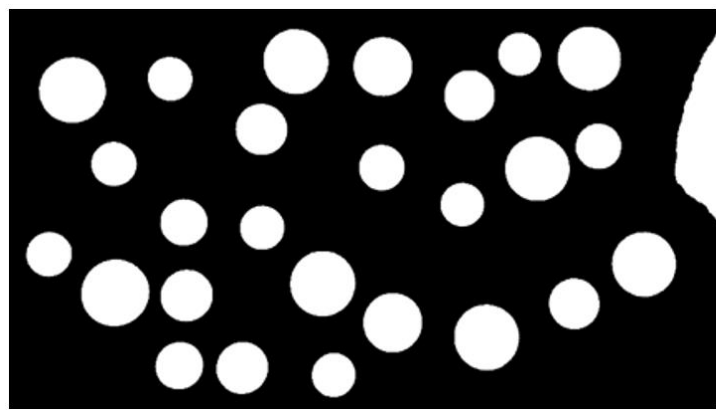

(a)

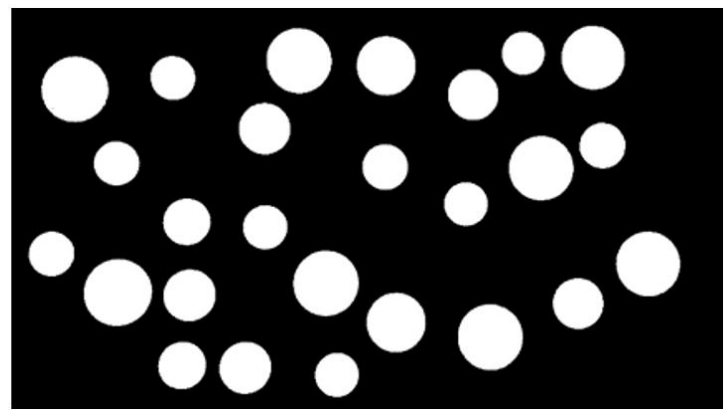

(b)

Şekil 7. (a) Filtreleme işlemi (b) Kenarlık nesnelerini kaldırma işlemi

Diğer işlem ise görüntünün kenarına dokunan nesneleri kaldırma işlemidir (Şekil 7.b). Bu işlem sonucunda görüntü, parçacık analizine uygun hale getirilmiştir. Görüntüdeki nesnelerin alanlarının tespit edilmesi için parçacık analizi işlemi uygulanmıştır. Her bir piksele karşılık bir birim kare geldiğinden dolayı ikili görüntüdeki nesnenin alanı o nesneye ait piksel sayısına eşittir ve böylelikle parçacık analizi metodu kullanarak her bir madeni paranın alanı hesaplanmıştır.

\subsection{Madeni Para Sınıflandırması}

Madeni paraların yüzey alanı bilgileri, blok diyagramda daha önce belirlenmiş aralıkta ise true bilgisine dönüştürülmüştür. Ardından bu bilgiler 1 sayı değerine dönüştürülerek toplanmış ve

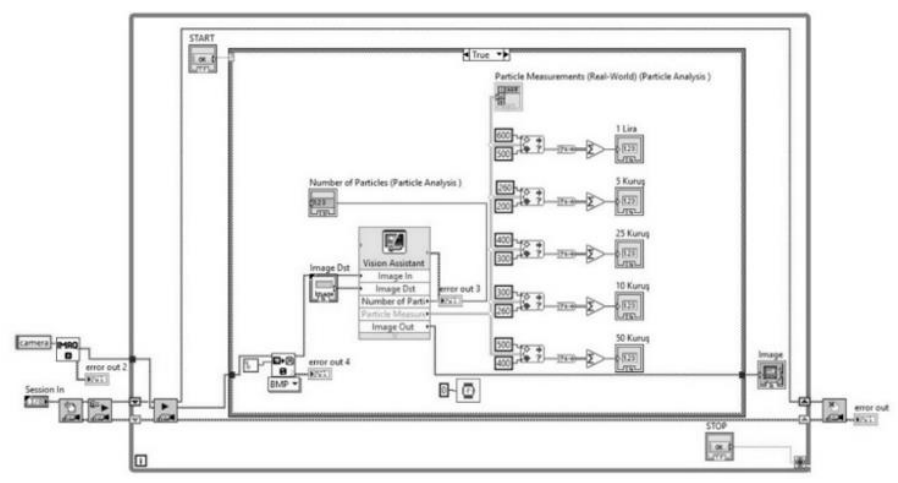

(a) her sınıftaki madeni paranın toplam sayısı ile yüzey alanı bilgileri ön panelde görüntülenmiştir. Gerçek zamanlı olarak anlık bir şekilde değişimlerin izlenebildiği veri toplama yazılımına ait LabVIEW Blok Diyagramı (kod ekranı) ve Ön Paneli (kullanıcı arayüzü) Şekil 8'de verilmiştir. İşlem başlatma ve durdurma butonları kullanılarak tasarlanan sistemde başlat butonuna basılmasının ardından madeni paralara tepeden bakan webcam aracılığı ile görüntüler anlık olarak elde edilmeye başlanmakta ve belirlenen aralıklarda olan alanlar $1 \mathrm{TL}, 50 \mathrm{Krş}, 25 \mathrm{Krş}, 10 \mathrm{Kr}$ ş ve $5 \mathrm{Krş}$ şeklinde sinıflandirılarak ön panel arayüzünde görüntülenmektedir. Şekil 8'de genel kod yapısı ve kullanıcı arayüzü sunulan program parçasına ait örnek bir madeni para diziliminin yüzey alanı değerleri ve her sınıfa ait toplam madeni para sayısı sonuçları Tablo 1'de gösterilmiştir.

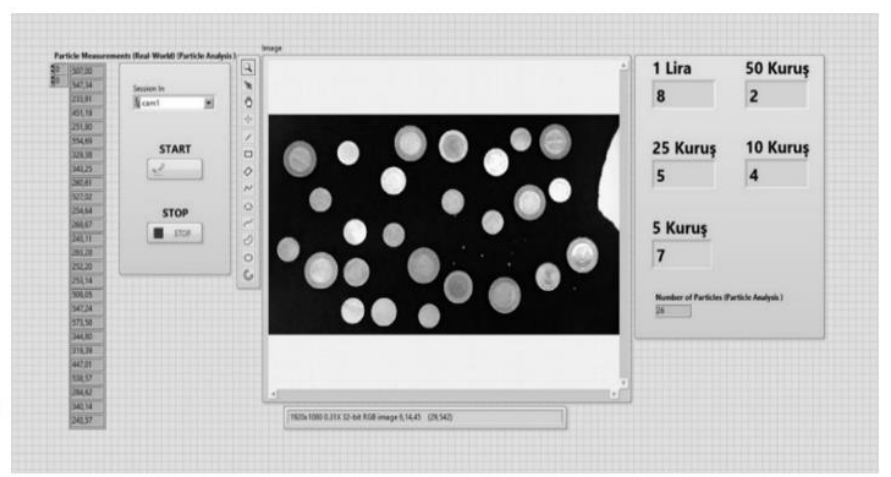

(b)

Şekil 8. (a) Blok Diyagram, (b) Ön Panel

Tablo 1. Parçacık analizi ve sınıflandırma sonuçları

\begin{tabular}{|c|c|c|c|c|c|}
\hline Madeni & $1 \mathrm{TL}$ & 50 kuruş & 25 kuruş & 10 kuruş & 5 kuruş \\
\hline \multirow{8}{*}{$\begin{array}{l}\text { Paraların Yüzey Alanlarl } \\
\left(\mathrm{mm}^{2}\right)\end{array}$} & 506,99572 & 451,19107 & 329,38163 & 260,61265 & 233,9098 \\
\hline & 547,34182 & 447,0096 & 343,2541 & 269,67203 & 251,7997 \\
\hline & 554,6913 & - & 344,80083 & 283,27856 & 254,64304 \\
\hline & 527,02461 & - & 319,38631 & 284,61973 & 243,10757 \\
\hline & 509,05197 & - & 340,13559 & - & 252,20415 \\
\hline & 547,24351 & - & - & - & 253,13816 \\
\hline & 573,58431 & - & - & - & 243,56816 \\
\hline & 538,5706 & - & - & - & - \\
\hline Toplam Adet & 8 & 2 & 5 & 4 & 7 \\
\hline
\end{tabular}




\section{Araştırma Sonuçları ve Tartışma}

Çalışmada kullanılan 5 çeşit madeni paraya ait 10 farklı ölçüm sonucu ve bu ölçümlere ait ortalama değerler Tablo 2'de sunulmuştur. Aynı sınıftaki madeni paraların yüzey alanlarının eşit çıkmamasının sebebi, ölçüm sırasında oluşan farklı $1 s ̧ 1 k$ yansımaları ve madeni paraların kameraya olan açısından kaynaklanmaktadır. Her bir sinıfta bulunan madeni para $16,50 \times 28,50 \mathrm{~cm}$ boyutlarındaki siyah ölçüm yüzeyinin farklı noktalarına konularak ölçümler gerçekleştirilmiş ve Tablo 2'de verilen sonuçlara ulaşıılmıștır. Tüm bu sınıflandırmalar sonucu belirlenen tolerans aral $1 \breve{g} 1 \pm \% 5,074$ olarak tespit edilmiştir. Tolere edilen bu aralık sonuçları, gerçeklenen yazılımın başarılı bir şekilde sınıflandırma yaptı̆̆ını göstermektedir.

Tablo 2. Görüntü işleme yazılımına ait alan ölçüm sonuçları

\begin{tabular}{|c|c|c|c|c|c|}
\hline & \multicolumn{5}{|c|}{$\operatorname{Alan}\left(\mathrm{mm}^{2}\right)$} \\
\hline Deney no & $1 \mathrm{TL}$ & 50 kuruş & 25 kuruş & 10 kuruş & 5 kuruş \\
\hline 1 & 539,00035 & 446,9262 & 356,48789 & 287,14167 & 237,83659 \\
\hline 2 & 505,20378 & 425,53077 & 350,55769 & 278,90725 & 232,78608 \\
\hline 3 & 522,66374 & 455,07144 & 347,23082 & 295,19815 & 252,75559 \\
\hline 4 & 545,73393 & 467,7514 & 336,49064 & 276,39904 & 236,44265 \\
\hline 5 & 555,3887 & 423,67297 & 357,54505 & 266,23528 & 241,84277 \\
\hline 6 & 532,68641 & 453,99566 & 348,81843 & 281,80157 & 245,44727 \\
\hline 7 & 527,84165 & 458,93444 & 358,58304 & 279,45015 & 232,00171 \\
\hline 8 & 536,50974 & 443,66753 & 355,4415 & 289,87629 & 239,70782 \\
\hline 9 & 535,26118 & 447,56949 & 319,82186 & 293,4086 & 252,92995 \\
\hline 10 & 560,30891 & 466,3228 & 353,15646 & 281,16139 & 244,31182 \\
\hline Ortalama & 536,059839 & 448,94427 & 348,413338 & 282,957939 & 241,606225 \\
\hline
\end{tabular}

LabVIEW ortamında geliştirilen görüntü işleme yazılım sonuçlarının gerçek dünya verileri ile test edilmesi amacıyla ölçüm hassasiyeti $0,03 \mathrm{~mm}$ ve ölçüm aralığı 0-150 mm/0-6" olan
Accud dijital kumpas ile gerçekleştirilen ölçüm sonuçlarına Tablo 3’te yer verilmiştir. $\mathrm{Bu}$ ölçümler gerçekleştirilirken alan hesaplamasında $\pi=3,14159$ olarak alınmıştır.

Tablo 3. Deneysel verilerin kumpas ölçüm sonuçları ile karşılaştırılması

\begin{tabular}{|l|l|c|c|c|c|c|}
\hline \multicolumn{2}{|c|}{ Ölçüm türü } & $\mathbf{1 ~ T L}$ & $\mathbf{5 0}$ kuruş & $\mathbf{2 5}$ kuruş & $\mathbf{1 0}$ kuruş & 5 kuruş \\
\hline $\begin{array}{l}\text { Kumpas ölçüm } \\
\text { sonuçlarl }\end{array}$ & Çap $(\mathrm{mm})$ & 26,16 & 23,82 & 20,39 & 18,4 & 17,43 \\
\cline { 2 - 7 } & Alan $\left(\mathrm{mm}^{2}\right)$ & 537,48332 & 445,62857 & 326,53066 & 265,90418 & 238,60761 \\
\hline $\begin{array}{l}\text { Deneysel ortalama } \\
\text { olçüm sonuçları }\end{array}$ & Çap $(\mathrm{mm})$ & 26,60 & 24,46 & 21,93 & 19,79 & 18,21 \\
\cline { 2 - 7 } & Alan $\left(\mathrm{mm}^{2}\right)$ & 536,05983 & 448,94427 & 348,41334 & 282,95794 & 241,60623 \\
\hline
\end{tabular}

Şekil 9'da, ortalama deney sonuçlarının alan cinsinden test ölçümleri ile karşıllaştırılmalı sonuçları veriliştir.

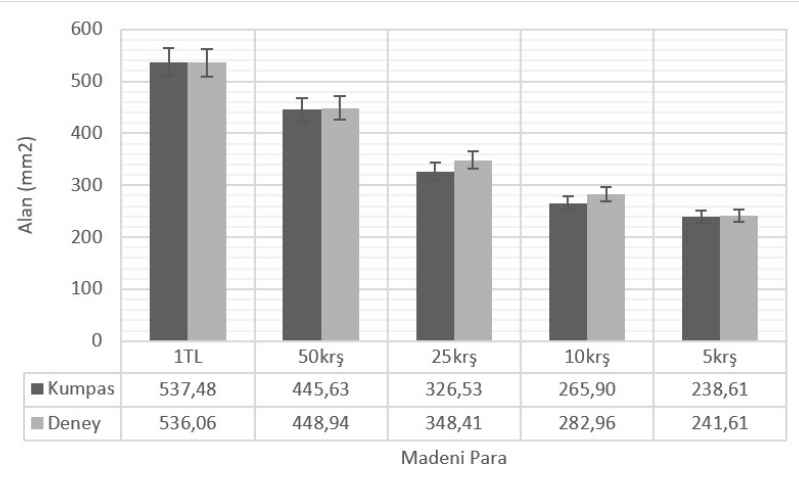

Şekil 9. Deney ve test verilerinin alan cinsinden karşılaştırması

Tablo 3'te verilen ölçüm sonuçlarına ait yüzde ortalama doğruluk oranları her bir sınıflandırmayı kapsayacak biçimde Şekil 10'da sunulmuştur. Şekilden anlaşılacağı üzere ölçümü gerçekleştirilen nesnenin boyutunun küçülmesi ile yüzde başarım oranında da bir düşüş gözlemlenmiştir. Bu sapma değerinin nedeni, kameranın ölçüm yüzeyine olan uzaklı̆̆ ve deney ortamının ışık şiddetidir.

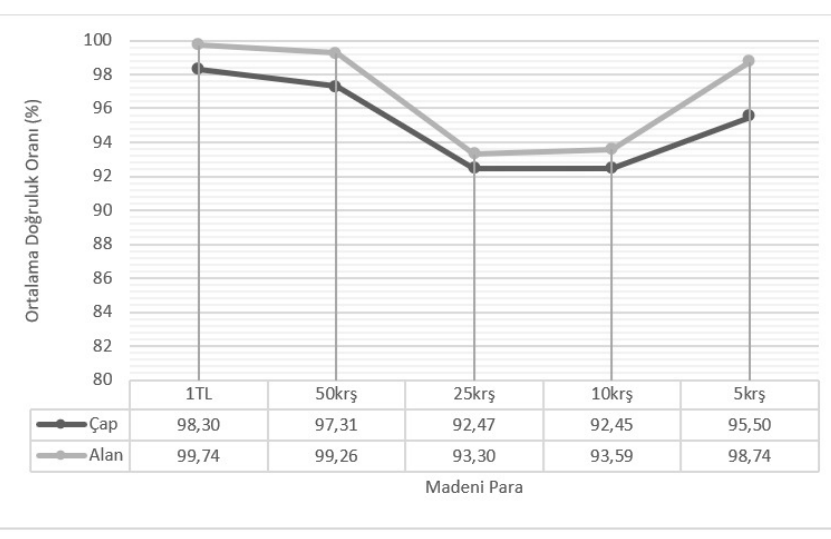

Şekil 10. Yüzde başarım

Sonuç olarak farklı sayılarda, 5 çeşit madeni para üzerinde test ve deneyleri gerçekleştirilen bu çalışma göstermektedir ki, geliştirilen yazılım endüstriyel sahada gerçek zamanlı veri okuma işlemlerinin gerçekleştirilmesinde özellikle alan bilgisi gerektiren durumlarda oldukça fayda sağlayacağı düşünülmektedir. Madeni paraların yüzey bilgisi (yazı, tura) gözetmeksizin alan bilgisi referans alınarak yapılan ölçümler sonucunda elde edilen yüzde başarımların sunulduğu bu çalışmanın konu ile ilgili alanlarda çalışma yapan araştırmacılara ve ticari ürün geliştiricilerine fayda sağlaması hedeflenmektedir. 


\section{Teşekkür}

$\mathrm{Bu}$ çalı̧̧manın gerçekleştirilmesinde her türlü imkânı sağlayan Robot Teknolojileri ve Ak1llı Sistemler Uygulama ve Araștırma Merkezi (ROTASAM)'a ve Doktor Öğretim Üyesi Mustafa Çağrı Kutlu'ya teşekkür ederiz.

\section{Kaynakça}

Atmaca, V., (2005). Örme kumaşlardaki üretim hatalarının görüntü işleme teknikleri ile otomatik tespiti ve sinfflandırılması. Yüksek Lisans Tezi, İstanbul Teknik Üniversitesi, İstanbul.

Bayram, R. B. \& Yılmaz E. (2019). Gömülü sistem tabanlı bir hatalı ürün tespit sistemi. Uludağ Üniversitesi Mühendislik Fakültesi Dergisi, 24(1), 391-400. https://doi.org/10.17482/uumfd.525696

Burkert, F., Butenuth, M. \& Ulrich, M.(2011). Real-time object detection with sub-pixel accuracy using the level set method. The Photogrammetric Record, 26(134), 154-170. https://doi.org/10.1111/j.1477-9730.2011.00633.x

Güvenoğlu, E. \& Bağırgan, M. (2019). Shearlet dönüşümü ve görüntü işleme teknikleri kullanarak kot kumaş üzerinde gerçek zamanlı hata tespiti. El-Cezeri Fen ve Mühendislik Dergisi, 6(3), 491-502, 2019.

National Instruments, (2005). NI Vision,: NI Vision for LabVIEW Tм User Manual, Part Number: 371007B-01. Erişim adresi https://www.ni.com/pdf/manuals/371007b.pdf

National Instruments, (2003a). IMAQ Tм. IMAQ Vision Concepts Manual, Part Number: 322916B-01. Erişim adresi https://www.ni.com/pdf/manuals/322916b.pdf

National Instruments, (2003b). LabVIEW Tм. User Manual, Part Number: $\quad 320999 \mathrm{E}-01 . \quad$ Erişim adresi https://www.ni.com/pdf/manuals/320999e.pdf

Ozan, M. (2019). Yumurta üretim tesisleri için görüntü analiz sisteminin geliştirilmesi ve uygulanmast. Yüksek Lisans Tezi, Konya Teknik Üniversitesi, Konya.

Ozkaya, U., Ozturk, S., Akdemir, B., \& Sevfi, L. (2018). An efficient retinal blood vessel segmentation using morphological operations. In 2018 2nd International Symposium on Multidisciplinary Studies and Innovative Technologies (ISMSIT). $1-7 . \quad$ IEEE. https://doi.org/10.1109/ISMSIT.2018.8567239

Özkan, H. (2012). Hayvansal üretim endüstrisinde görüntü işleme tabanlı gerçek zamanlı bir kalite kontrol uygulaması. Yüksek Lisans Tezi, Selçuk Üniversitesi, Konya.

Öztürk, Ş. (2015). Cam üretim hatalarının görüntü işleme tabanlı bulunması. Yüksek Lisans Tezi, Selçuk Üniversitesi, Konya.

Pınar, Z., Gülağız,F. K., Altuncu, M. A. \& Şahin, S. (2020). Denim kumaşlarda görüntü işleme ile hata tespiti. $B E \ddot{U}$ Fen Bilimleri Dergisi, 9(4), 1609-1620. https://doi.org/10.17798/bitlisfen.595389

Şenel, F. A. \& Çetişli, B. (2015). Görüntü işleme ve beş eksenli robot kol ile üretim bandında nesne denetimi. Pamukkale Üniversitesi Mühendislik Bilimleri Dergisi, 21(5), 158-161, 2015. https://doi.org/10.5505/pajes.2014.96658

Tsai, S. H. \& Tseng, Y. H. (2012). A novel color detection method based on hsl color space for robotic soccer competition. Computers and Mathematics with Applications, 64(5), 12911300. https://doi.org/10.1016/j.camwa.2012.03.073

Yıldırım, Ş. \& Ozak, B. (2018). Desing and experimental applications of material classification prototype system.
Journal of New Results in Engineering and Natural Science, $8,148-156$.

Yoldaş, M. \& Sungur, C. (2020). Alüminyum ekstrüzyon profillerinin hassas kesit ölçümlerinin görüntü işleme teknolojisi ile gerçekleştirilmesi. Avrupa Bilim ve Teknoloji Dergisi, (Özel Say1), 190-195. https://doi.org/10.31590/ejosat.803308

Zhan, C., Duan, X., Xu, S., Song, Z. \& Luo M. (2007). An improved moving object detection algorithm based on frame difference and edge detection. Fourth International Conference on Image and Graphics, 519-523. https://doi.org/10.1109/ICIG.2007.153 